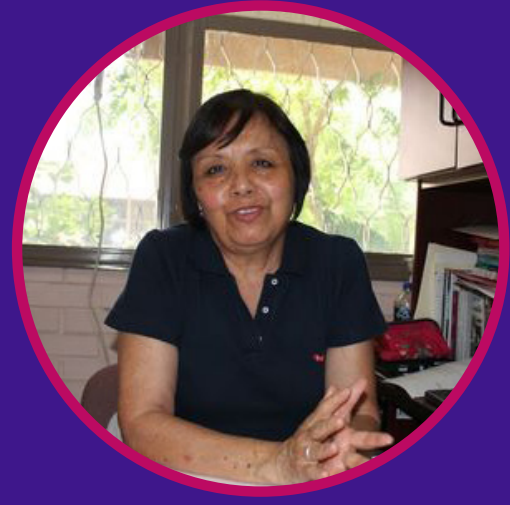

\title{
Los medios de comunicación en los procesos electorales
}

\author{
The media in electoral processes
}

\section{Dra. Blanca Chong López}

Universidad Autónoma de Coahuila blancachong@uadec.edu.mx

Recibido: 17 de enero de 2018.

Received: January 17th 2018.

Aceptado: 2 de mayo de 2018.

Accepted: May 2nd 2018.

cc) (i) $\ominus$ Esta obra está bajo una licencia internacional Creative EY NC ND Commons Atribución-NoComercial-SinDerivadas 4.0.

DOI: https://doi.org/10.21555/rpc.voi1.2301

Cómo citar: Chong López, B. . (2019). Los medios de comunicación en los procesos electorales. RPC, 1(1), 41-50. https:// doi.org/10.21555/rpc.voi1.2301

Revista Panamericana de Comunicación, Año 1, N. 1, enero-diciembre 2019, pp. 41-50.

\section{RESUMEN}

La importancia de los medios de comunicación en la conformación de la opinión pública no es un asunto de menor importancia. Las campañas políticas son momentos claves en los cuales se genera información sobre candidatos y sus estrategias. La investigación sobre campañas electorales refiere el papel central de los medios de comunicación, particularmente la televisión, en las modernas estrategias de campaña alrededor del mundo. En México, el uso intensivo de los medios como uno de los canales de comunicación más importantes en campañas electorales se dio en la elección federal de 1994, en la cual tuvieron por primera vez un papel más relevante en la competencia político electoral. En el presente artículo, tratamos de analizar las cuestiones que anteceden y obtener conclusiones válidas para el mejor conocimiento de estos fenómenos.

Palabras-clave: Elecciones / Medios de comunicación/ Comunicación política / Procesos electorales.

\section{ABSTRACT}

The role of the media in shaping public opinion is not a matter of minor importance. Political campaigns are key moments in which information about candidates and their strategies is generated. Research on electoral campaigns refers to the central role of the media, particularly television, in modern campaign strategies around the world. In Mexico, the intensive use of the media as one of the most important communication channels in electoral campaigns took place in the federal election of 1994, in which they had for the first time a more relevant role in electoral political competition. In the present article, we try to analyze the above issues and obtain valid conclusions for the best knowledge of these phenomena.

Key Words: Elections / Media / Political communication / Electoral processes. 
L as imágenes que nos formamos acerca del mundo que nos rodea tienen distintos orígenes, y entre esas diversas fuentes de conocimiento se ubican en un lugar destacado los medios de comunicación, especialmente la televisión, que a partir de su surgimiento a mediados del siglo pasado amplió la discusión en torno a la influencia de los medios en la opinión pública.

Uno de los aspectos en los que se ha centrado el debate sobre la incidencia de los medios en la opinión pública es que los medios son considerados elementos necesarios para la libertad de expresión y el derecho a la información, pero también se les concibe como poderes fácticos, pues su poder puede llegar a competir con los poderes establecidos. Se les ha estudiado a partir del desplazamiento de los debates y la propaganda a las pantallas, reconociendo a la televisión un gran poder. La visibilidad mediática es tan importante que hoy se considera que lo que no está en los medios no existe para el público, pues sólo haciendo llegar mensajes a los ciudadanos, se podrá influir en sus decisiones. Debido a la visibilidad que conceden para la esfera pública, los medios y en especial los electrónicos, son la plataforma moderna del debate y la propaganda (Castillo, 2014).

Dentro de la política, los procesos electorales representan uno de los momentos más importantes en las sociedades democráticas. En esos contextos un factor destacado lo constituyen los medios de comunicación, al servir no solo para que los partidos expongan sus posturas, sino también como canales a través de los cuales la sociedad demuestra sus opiniones sobre las diversas propuestas políticas. Ello ha tenido como consecuencia una creciente "mediatización" en el desarrollo de los procesos de elección (Canseco, 2012).

Las campañas electorales permiten que los votantes puedan definir sus preferencias a través de los mensajes que en ellas se generan. Son fuentes cada vez más importantes de información en el flujo de comunicación política. Las noticias presentadas en los distintos medios de comunicación influyen en las percepciones públicas sobre los partidos, los líderes y los temas de debate electoral. En el ámbito político en el que se desarrolla una campaña, los medios pueden contribuir a definir una agenda que beneficie a un determinado partido, otorgando mayor presencia y protagonismo a los candidatos y al líder de ese órgano político, o enfatizando de un modo positivo sus características.

La importancia de los medios de comunicación en la conformación de la opinión pública no es un asunto de menor importancia. Las campañas políticas son momentos claves en los cuales se genera información sobre candidatos y sus estrategias.

\section{LOS EFECTOS DE LOS MENSAJES DE CAMPAÑAS ELECTORALES}

El estudio de los efectos de los mensajes de campaña en democracias recientes cobra relevancia porque pueden tener efectos diferentes -sobre la cultura política y la participación ciudadana- a los efectos moderados comúnmente encontrados en democracias desarrolladas (Díaz Jiménez, 2016). El efecto desmovilizador de los mensajes políticos a través de los medios puede ser acentuado por las características propias del contexto político e informativo de las democracias no desarrolladas, que con frecuencia muestran bajos niveles de identificación del electorado con los partidos y fuentes limitadas de información, debido al predominio de la televisión como fuente de información política.

Existe un importante debate teórico acerca de los efectos de los mensajes políticos de los medios y las campañas en las actitudes cívicas y la participación de los ciudadanos. Por una parte, las teorías del malestar mediático que sostienen que existe un impacto negativo de esos mensajes sobre las actitudes políticas cívicas de la ciudadanía, mientras que las teorías de la movilización señalan que existe un efecto positivo y benéfico sobre esas actitudes. Sin embargo, la mayoría de los estudios sobre el tema se han desarrollado en democracias avanzadas, sin analizar si esas teorías tienen sustento en democracias en desarrollo, como la que existe en México.

La investigación sobre campañas electorales refiere el papel central de los medios de comunicación, particularmente la televisión, en las modernas estrategias de campaña alrededor del mundo. En México, el uso intensivo de los medios como uno de los canales de comunicación más importantes en campañas electorales se dio en la elección federal de 1994, en la cual 
tuvieron por primera vez un papel más relevante en la competencia político electoral.

Durante casi todo el siglo XX las campañas electorales se distinguieron por su orientación local y los eventos basados en el contacto directo entre candidatos y electores. En este período las comunicaciones de campaña se limitaron a los discursos de los candidatos, anuncios en la prensa escrita y posteriormente, con la expansión de la radio y la televisión, incluyeron también entrevistas en los noticiarios locales y nacionales.

Aunque la eficacia de las tácticas y estrategias de campaña basadas en el uso intensivo de los medios es aún motivo de debate entre los estudiosos de la comunicación política y del comportamiento político electoral, existe un importante número de investigaciones que señalan que junto a las redes sociales y a otras organizaciones secundarias los medios tienen un papel cada vez más importante como intermediarios electorales entre partidos y votantes en México. Los hallazgos de esas investigaciones demuestran, en general, que el modelo de los "efectos limitados", que influyó de manera importante en la investigación sobre el impacto de los medios en el comportamiento político en democracias avanzadas, puede no ser totalmente adecuado para explicar el impacto de los medios y las comunicaciones de campaña en nuevas democracias como la mexicana.

Según Díaz Jiménez (2016), existen factores estructurales relacionados con el ambiente contextual en el cual se desarrollan las campañas electorales en México que podrían favorecer el impacto negativo de la exposición a los mensajes políticos de los medios sobre el involucramiento político de los ciudadanos. Entre esos factores destacan los siguientes:

» La estructura de propiedad predominantemente privada y grandemente concentrada del sistema de medios (especialmente en el sector de televisión abierta), el cual se caracteriza por la elevada exposición a la televisión y la limitada circulación de periódicos entre la población, alto grado de consumo de entretenimiento televisivo en relación con el bajo consumo de noticias en periódicos y revistas, y el predominio de la televisión como la principal fuente de información política.
» El proceso gradual de desalineamiento en el sistema de partidos, entendido como la disminución en los niveles de identificación partidista entre el electorado (particularmente de la identificación partidista fuerte) y el aumento de los electores independientes 0 apartidistas.

» Las reformas al marco regulatorio de las campañas electorales en México (especialmente la Reforma Electoral de 2007-2008), las cuales favorecen a la espotización de las campañas, es decir, la sobreexposición a los canales directos de comunicación política como los anuncios electorales televisivos entre el electorado, consecuencia de las posibilidades de acceso a medios para los partidos políticos que establece la nueva legislación. Este aspecto se retomará más adelante.

\section{LA ESPECTACULARIZACIÓN DE LA POLÍTICA}

En décadas recientes la participación cada vez mayor de los medios de comunicación en la política ha tenido como resultado la "mediatización" de la misma, es decir una situación en la que los medios masivos, sobre todo los audiovisuales, imponen su lógica en la construcción de la realidad política. Además, una consecuencia de esa "mediatización" de la política en las campañas electorales es lo que se ha denominado como "espectacularización de la política” o "infoentretenimiento", que implica la utilización de códigos, figuras y lógicas de entretenimiento y del mundo del espectáculo en la política. Los contendientes buscan aparecer sobre todo en la televisión, lo que favorece que se realicen actos de campaña y declaraciones centradas más en el espectáculo y la dramatización que en información que permita evaluar las propuestas de los candidatos. De esta forma las campañas políticas se basan en una "lógica mediática" y se convierten en elemento de entretenimiento, no de información para la toma de decisiones de quienes emiten su voto (Echeverría y Chong, 2014). Acontecimientos de contenido relevante para entender los procesos políticos se presentan como entretenimiento, desvirtuando su esencia de tal forma que proporcionan representaciones muy distintas al acontecimiento original. 
Se trata de una tendencia que ha generado controversia y recibido numerosas críticas en relación con el potencial efecto de despolitización en las audiencias por la proliferación de formatos y mensajes mediáticos que mezclan información sobre acontecimientos políticos con elementos de entretenimiento. La trivialización de la política mediante el énfasis de contenidos vinculados a escándalos y conflictos de los políticos, en menoscabo de las problemáticas políticas y propuestas de campaña, además de disminuir el aprendizaje de los votantes sobre lo que está en juego en la elección, incrementa la desconfianza hacia el sistema político o al régimen democrático mismo (Echeverría, 2017).

\section{TRANSFORMACIONES DE LOS MEDIOS Y POLÍTICA}

Para comprender la influencia de los medios en la política es necesario tener presente cómo se fueron integrando a esta actividad. Si se consideran las grandes transformaciones que los medios de comunicación masivos significaron para la tradición de la política antigua, es posible observar cuatro etapas básicas en el desarrollo y aprovechamiento de los medios de comunicación para la política y una quinta etapa en sus inicios (Casas, 2011). En las líneas siguientes se refieren algunas de las implicaciones para la actividad política y el desarrollo social como consecuencia de la incorporación de los medios a la política.

\section{PRIMERA ETAPA: LA DEL ADOCTRINAMIENTO DE LAS MASAS}

La imprenta fue la gran transformación tecnológica del siglo XV. A pesar del impacto de la utilización de la imprenta en la difusión del conocimiento, fue hasta finales del siglo XIX y principios del XX que la tecnología fue aprovechada para llevar la información política a las masas a través de la prensa y la distribución de libros populares y panfletos, o con la introducción de la tecnología aplicada a la información y el entretenimiento, como en el caso del cinematógrafo o la radio. Más tarde llegaría la televisión y los debates transmitidos por ese medio, que modificaron los estándares de la política al llevarla al interior de los hogares, ofreciendo al electorado la posibilidad de contrastar las posturas de los candidatos para reforzar una decisión de voto.

A diferencia de las épocas anteriores, en las que el ciudadano debía acudir a la plaza pública para escuchar el discurso del político, con la prensa, el cine, la radio y la televisión el político pudo acercarse al ciudadano. Con ello la fuerza del discurso como medio de articulación ideológica perdió su vigor, al pasar de la precisión del lenguaje a la oralidad y simbolización gestual propias de la imagen.

\section{SEGUNDA ETAPA: LA DE LA ORGANIZACIÓN DEL MERCADO POLÍTICO}

La mercadotecnia política se convirtió en el arte de la administración de los recursos para lograr el impacto deseado en la política, al responder a la necesidad de crear productos para el mercado masivo. Por décadas las fórmulas de la mercadotecnia política serían seguidas fielmente para lograr la mayoría de votos. A partir de la segunda mitad del siglo XX, el ciudadano ya no sería considerado uno más entre los posibles electores, sino el target, el público específico de los esfuerzos de posicionamiento de la marca.

Este cambio se debe en parte a la evolución tecnológica de los medios. La prensa dejó su carácter universalista para producir suplementos especiales de crítica y análisis dirigidos a segmentos de mercado específicos. La televisión y la radio evolucionaron para dar paso a las estaciones de paga transmitidas por cable, mientras hacía su aparición la red de redes, la Internet, un nuevo medio mucho más influyente y expansivo.

Internet, con el correo electrónico como su primera herramienta, echó por tierra la primacía de los medios tradicionales, al hacer posible el intercambio de información a gran escala sin depender de los circuitos informativos y de poder de las grandes cadenas de noticias. El correo electrónico significó la posibilidad de llegar directamente al elector, con un lenguaje más directo, ajeno a los cánones de la mercadotecnia y la publicidad política. Luego aparecerían las páginas web, que en sus inicios fueron utilizadas para fines políticos como simples escaparates de información. 
A diferencia de otros medios, Internet combina las cualidades de un medio masivo de gran alcance, como la televisión, con la posibilidad de un intercambio personalizado de información entre determinados individuos.

Con una diferencia fundamental respecto de las empresas privadas de medios, que nacieron con una vocación comercial, Internet nació como un recurso gratuito. Hoy día constituye el recurso de búsqueda de información más utilizado en el mundo. Las páginas web constituyen el mejor foro para la difusión de las plataformas políticas e ideológicas de partidos políticos, candidatos y gobernantes.

\section{TERCERA ETAPA: LA DE LA BÚSQUEDA DE LA RESPUESTA DEL RECEPTOR}

El desarrollo de Internet ha permitido incrementar el grado de interacción que permite al usuario. Aplicaciones como los navegadores y los motores de búsqueda han sido fundamentales en el desarrollo de la comunicación política, al permitir rastrear los esfuerzos de contacto de los ciudadanos y suministrar a los electores, por parte de instituciones y organizaciones políticas, información dosificada.

El desarrollo de la tecnología de la telefonía ceIular ha posibilitado que actualmente los teléfonos móviles incorporen herramientas que anteriormente estaban disponibles solo a través de una computadora. Hoy la aplicación de la telefonía celular con fines políticos es evidente, ha incrementado la capacidad de reacción del político, pero su verdadero impacto se basa en todas las formas de incorporación a la comunicación móvil que ofrece. El uso de celulares en las campañas políticas los convierte en la herramienta de movilización política más importante de las elecciones modernas.

\section{CUARTA ETAPA: LA DEL EMPODERAMIENTO CIUDADANO}

Etapa conocida como la de e-política, se caracteriza por la explotación de estrategias políticas a través de Internet. El contenido de los mensajes es más dinámico que el de los medios anteriores y responde a la necesidad del político de mantenerse en contacto directo con el ciudadano. Sin embargo, si bien la mercadotecnia política y los políticos han ido incorporando las herramientas tecnológicas, también los ciudadanos o electores han aprovechado su uso con fines distintos.

Hoy la ventaja de la comunicación a través de la red es la participación del usuario. Ya no es suficiente que el candidato haga públicas sus propuestas, sino que tendrá que aceptar también la opinión de los ciudadanos.

Junto con otras herramientas propias de la web 2.0 las redes sociales han sido ampliamente utilizadas en las actividades políticas, tanto para hacer promoción política o ideológica como para generar una crítica hacia ella. Lo esencial de la política en esta etapa es hacer llegar la información a la gente apropiada, pero también permitir que se exprese y aproveche su capacidad de retransmisión, extendiendo el impacto del mensaje.

La gran diferencia con los medios de información y comunicación de la política anterior es que las herramientas actuales hacen posible que el individuo participe como ciudadano. La pregunta es si esto abre la posibilidad para una auténtica ciberdemocracia.

\section{QUINTA ETAPA: LA DE LA REFORMULACIÓN DEL SENTIDO DEMOCRÁTICO}

La web 2.0 ha representado un gran cambio en la manera en la que se había desarrollado la política en tiempos recientes. Sin embargo, al igual que la tecnología, la política deberá transformarse debido a las posibilidades que ofrecerán las nuevas herramientas, que implican, por ejemplo, la evolución de la red de redes hacia la Inteligencia Artificial, que posibilita que una red de computadoras responda a consultas de sus usuarios a partir de mecanismos como el reconocimiento de escritura, reconocimiento de voz y de patrones.

En atención a las posibilidades que ofrecen los nuevos medios, la noción de política deberá ser reconstruida. En el marco de las nuevas tecnologías de información y comunicación el antiguo espacio donde se genera la opinión pública, en el que ocurre la búsqueda de consensos, será reemplazado por la cultura política de la pluralidad. 


\section{LA REGULACIÓN DE LOS MEDIOS EN LOS PROCESOS ELECTORALES}

La presencia cada vez mayor de los medios en los procesos políticos en México ha hecho necesario establecer normas para su utilización por parte de los distintos actores. Lograr condiciones de equidad en el desarrollo de las contiendas electorales, sobre todo en el acceso de los partidos y candidatos a los medios de comunicación, fue uno de los principales reclamos de los partidos de oposición hacia los organismos electorales durante el siglo pasado. A partir del proceso electoral de 1988 que generó una profunda crisis de credibilidad hacia el gobierno federal y sus organismos electorales, los partidos de oposición presionaron al aparato que había gobernado el país por décadas, el cual se vio obligado a introducir algunas modificaciones sustantivas en la legislación electoral (Aceves, 2010). Un aspecto fundamental en el reclamo de los partidos de oposición por la equidad tenía que ver con el acceso en las campañas políticas a los medios de comunicación: la posibilidad de la compra de espacios publicitarios para la difusión de sus mensajes en los medios comerciales y la inclusión de sus campañas en la cobertura informativa que los medios realizaban de los procesos electorales.

Fue hasta la reforma de 1993 al Código Federal de Instituciones y Procedimientos Electorales (COFIPE), promulgado en 1990, cuando se reglamentó la contratación de espacios comerciales en los medios electrónicos, para difundir publicidad política en las campañas electorales. En relación con la cobertura informativa de los medios en las elecciones, con la reforma de 1996 se estableció en el COFIPE la realización de "monitoreos muestrales sobre las campañas de los partidos políticos en los espacios de noticias de los medios de comunicación”. A parir de la reforma política constitucional de 1996 las campañas presidenciales en México se hicieron más intensas y competidas al crearse las condiciones necesarias de certidumbre y equidad, así como la autonomía jurídica y financiera del órgano electoral. Así mismo, la ampliación de los recursos financieros a los partidos políticos y su mayor acceso a los espacios de radio y televisión les ha permitido tener una mayor capacidad para la promoción de candidaturas y propuestas políti- cas a distintos sectores de la ciudadanía (Aceves, 2010, Meyer, Ahuactzin, Ríos, 2014).

Esos intentos regulatorios mostraron ser ineficaces en el proceso electoral de 2006 en México, en el que se incrementó la publicidad negativa y la guerra sucia, con el resultado de una nueva crisis de credibilidad en las instituciones electorales. Las elecciones presidenciales del 2006 mostraron deficiencias importantes en el sistema electoral mexicano y revelaron un significativo rezago por parte del Estado en la regulación de las campañas políticas y la garantía de equidad en los procesos electorales. En esas elecciones los distintos actores políticos incurrieron en viejas prácticas tanto en la operación electoral como en el acceso a medios de comunicación, particularmente la radio y la televisión (Pareja, 2014).

En ese proceso electoral de 2006, donde fue evidente la compra de gran cantidad de espacios para la transmisión de spots por parte de los partidos políti$\cos$, la cual benefició sobre todo a las dos grandes televisoras del país (AMEDI, 2013), se hizo evidente que la influencia creciente de los medios electrónicos en las contiendas políticas ha generado efectos opuestos a la democracia, al propiciar la adopción de patrones de propaganda política y electoral que imitan o reproducen los que utiliza el mercado para promover mercancías y servicios.

En esas circunstancias la política y la competencia electoral quedan subordinadas no solo a modelos de propaganda, que no les son propios, sino al riesgo de influencia de los dueños o concesionarios de estaciones de radio y canales de televisión (o bien de otros grupos de poder económico que puedan reflejarlo en esos medios de comunicación) en sus audiencias, al destacar la imagen de aquellos candidatos que sean afines a sus intereses.

Con el fin de otorgar a los partidos políticos condiciones más equitativas para la difusión de mensajes audiovisuales durante las campañas electorales, entre el 12 y el 14 de septiembre del 2007, el Congreso aprobó una reforma a la Constitución Política Mexicana que modificó nueve de sus artículos y se adecuaron disposiciones en el Código Federal de Instituciones y Procedimientos Electorales (COFIPE) para normar las atribu- 
ciones del entonces Instituto Federal Electoral, IFE, en el acceso de los partidos políticos a radio y televisión.

La Reforma Electoral que entró en vigor a inicios de 2008 se concentró precisamente en definir un marco jurídico que permitiera un proceso con equidad sobre todo en lo que se refiere a los medios, se le otorgó un status prioritario a la arena audiovisual en la disputa electoral (Pareja, 2014). Así mismo, se le otorgó al Estado un papel más activo en la regulación de las campañas electorales, de manera particular en radio y televisión.

Entre los cambios destacaron las facultades que tendría el IFE para la organización de las elecciones. Resalta también la reducción de los períodos de campañas electorales y la reglamentación de la difusión de propaganda en medios electrónicos, que controla la intervención de actores no autorizados en la contienda como autoridades de gobierno y el sector privado, así como el acceso y uso de los partidos políticos a los tiempos del Estado en radio y televisión.

Con la reforma se buscaba propiciar el desarrollo de las campañas políticas en condiciones de mayor equidad, garantizando un acceso más equitativo a los medios electrónicos, sobre todo a la televisión. Esta reforma modificó las reglas del modelo de comunicación político electoral en México. El principal cambio fue la prohibición a los partidos para contratar espacios publicitarios directamente con los medios y la difusión de mensajes políticos utilizando tiempos del estado. Toda la publicidad política en los medios electrónicos quedó bajo el control del Instituto Federal Electoral, hoy Instituto Nacional Electoral (INE), el cual se encarga no solo de la distribución de los espacios a los partidos, de acuerdo a los criterios legalmente establecidos, sino de todo el proceso de entregar tanto los spots como las pautas de programación a todos los concesionarios y permisionarios de medios electrónicos. Además, debe implementar un mecanismo para supervisar su estricto cumplimiento. El propósito de la reforma fue garantizar la equidad entre los actores políticos para el acceso a los medios electrónicos y evitar que el dinero fuera un elemento determinante para estar en posibilidades de dar a conocer la oferta electoral. Se trataba de evitar también que instancias ajenas a los procesos de los co- micios tuvieran injerencia para tratar de incidir en las preferencias electorales (Aceves, 2010; AMEDI, 2013).

La reforma también ofreció una respuesta a la demanda de algunos sectores de la sociedad para que las campañas electorales fueran más cortas y se redujera el gasto de recursos públicos por parte de los partidos políticos, que en su mayor parte aplicaban sus recursos en la contratación de spots en los medios electrónicos.

Sin embargo, el cambio se limitó a lo que se refiere al acceso, sin atender lo que tiene que ver con la responsabilidad social de los medios sobre la cobertura informativa de las campañas políticas. Un aspecto positivo de la legislación, en relación con la cobertura noticiosa de los medios, es que obliga al organismo electoral a llevar a cabo "la realización de monitoreos de las transmisiones sobre las precampañas y campañas electorales en los programas en radio y televisión que difundan noticias". Los resultados que arrojan dichos monitoreos deberán ser difundidos por lo menos cada quince días, a través de los tiempos destinados a la comunicación social del Instituto Federal Electoral.

Algunos de los problemas que ha tenido la reforma es que los cambios se concentraron en el formato spot como elemento central para la comunicación política, al reglamentar su uso, distribución, administración y contenido. Sin considerar que la naturaleza del spot simplifica la discusión pública, porque se reduce la información a 30 segundos, la generaliza y no existe profundidad en los argumentos, los spots centran la comunicación en la imagen en menoscabo de la información y reflexión tanto de las propuestas como de los rasgos del candidato. Otros aspectos de comunicación política quedaron fuera de la reglamentación.

Existe también un vacío en la ley, la contratación de espacios para propaganda en el formato televisivo de mayor éxito en México, la telenovela, como lo describe ampliamente Pareja (2014).

Más recientemente, en 2014 se aprobó la reforma constitucional en materia política - electoral, que implica la evolución a una nueva autoridad electoral de carácter nacional. Uno de los principales objetivos de esta reforma es homologar los estándares con los que se organizan los procesos electorales federales y locales. El aspecto más sobresaliente de la reforma es la trans- 
formación del Instituto Federal Electoral en una autoridad de carácter nacional: el Instituto Nacional Electoral, INE. Con esta reforma se modificó de manera sustantiva el sistema electoral mexicano, con una distribución de competencias entre el INE y los organismos públicos locales electorales, lo que genera nuevas formas y reglas para ejercer la función electoral en el país (Soto, 2014).

Antes de esta reforma el sistema electoral mexicano estaba conformado como un sistema federal descentralizado, integrado por un subsistema nacional y por 32 subsistemas en las entidades federativas. A partir de la reforma constitucional de 2014 existe ahora un sistema nacional electoral que tiene un órgano constitucional autónomo, el INE, cuya encomienda principal es organizar los comicios.

\section{EL PROCESO ELECTORAL DEL 2012}

La campaña presidencial de 2012 puede ser considerada como "el proceso político de más amplia difusión mediática en la historia electoral de México y la de más alta saturación ciudadana" (Meyer, Ahuactzin, Ríos, Lara, López, Kuri, 2014, p. 5) debido a la estrategia institucional de promocionar a los candidatos y partidos a través de spots audiovisuales en todas las estaciones concesionarias y permisionarias de radio y televisión del país. Con base en las reformas 2007 - 2008 del COFIPE los partidos políticos aprovecharon el otorgamiento de los tiempos oficiales a los que el Estado tiene derecho en emisoras de radio y televisión, para transmitir durante los 90 días de campaña alrededor de 17 millones de mensajes sobre los candidatos en 2 mil trescientas estaciones del país. La producción de los spots estuvo a cargo de los partidos políticos, y el IFE por su parte administró y supervisó las pautas de transmisión en los distintos estados del país.

Así, en el proceso electoral de 2012 una vez más los medios de comunicación tuvieron un importante papel en la formación de opinión por parte de los ciudadanos. Si bien los tiempos asignados a cada partido o coalición en los noticiarios no necesariamente se refleja en los resultados electorales, pues una mayor cobertura informativa no implica un mayor número de votos hacia un candidato, por su enorme capacidad de penetra- ción los noticiarios de radio y televisión seguirán siendo una fuente fundamental de información para un gran número de mexicanos, lo que los convierte en verdaderos actores políticos. (Sosa, 2011).

En ese proceso electoral quedó demostrado que los noticiarios se están transformando en espacios de mayor "empoderamiento" y de negociación con las diferentes fuerzas políticas, a pesar de que se hayan establecido lineamientos de imparcialidad y equidad avalados por el IFE y los empresarios de la radio y la televisión (Sosa, 2011). Ante las restricciones establecidas en la reforma electoral de 2007 - 2008 para que puedan adquirir tiempos en los medios, los partidos políticos buscaron una mayor exposición en los espacios informativos, como una forma de salvar esas prohibiciones (Canseco, 2012). La clase política, consciente de las ventajas que le proporciona la televisión, se ha aliado con las televisoras para tratar de evadir la nueva legislación, por lo que es frecuente la venta de espacios en los noticiarios, que se convierten en infomerciales (Martínez y Yáñez, 2011).

Según la "Encuesta Nacional de Cultura Política y Prácticas Ciudadanas" (Encup) 2012, el 76\% de los mexicanos se informa sobre asuntos políticos principalmente a través de la televisión, $9 \%$ lo hace a través de la radio, $5.4 \%$ por medio de periódicos y $4.8 \%$ a través de internet. (Segob, 2012).

Por la forma en que se expone a los candidatos y sus propuestas, y la manera en que se trata en esos espacios informativos lo relacionado con dichos actores políticos, se puede conseguir que las personas acepten o rechacen al candidato, logrando así influir en la acción del voto, puesto que "Es difícil pensar... que una inversión multimillonaria, como lo es el marketing electoral, no tenga efecto alguno en la decisión de voto de los electores" (Macías, 2007, p. 302).

El análisis de los distintos componentes de comunicación mediática durante la campaña presidencial de 2012 refiere que el valor simbólico de los mensajes transmitidos por los candidatos participantes en la contienda sí fue un valor importante en la decisión de los ciudadanos independientes. Al ser la percepción ciudadana mayormente emotiva y esperanzadora, la decisión se centró más en la persona que en la propuesta (Meyer, Ahuactzin, Ríos, 2014). 


\section{PALABRAS FINALES}

En las elecciones de 2018 se elegirán Presidente de la República, 128 senadores y 500 diputados federales, además de 2,818 autoridades locales (El Economista, 2018). El gasto para los comicios federales y 30 locales ascenderá a 45 mil 620 millones de pesos (Urrutia, 2018).

Frente a un proceso electoral que se considera el más complejo de la historia de México por ser el primero del nuevo sistema nacional de elecciones, por la intensa competencia política que se vislumbra, la crisis de credibilidad que existe entre los ciudadanos hacia las instituciones electorales y los partidos políticos, la gran cantidad de ciudadanos que votarán por primera vez (más de 14 millones), entre otros factores, es necesario observar el papel que tendrán los medios de comunicación, tanto los tradicionales como los nuevos, surgidos a partir del desarrollo de las tecnologías de información y comunicación. Entre estos últimos, las redes sociales tendrán mayor actividad e influencia.

\section{REFERENCIAS}

» Aceves, F. (2010). La democracia no pasa por las pantallas: desigualdad, desequilibrio y ausencia de pluralismo en la cobertura informativa de las elecciones de 2009 en Jalisco. Quórum Académico, vol. 7, núm. 2, julio-diciembre. Disponible en http://www.redalyc.org/articulo. oa?id=199016268004 Fecha de consulta: 10 de enero de 2013.

» Asociación Mexicana de Derecho a la Información, (AMEDI), (2013). Perspectivas y evaluación del modelo de comunicación político-electoral en México. Revista Mexicana de Derecho Electoral, Especial sobre Observación Electoral 2012, núm. 4. Disponible en http://biblio.juridicas. unam.mx Fecha de consulta: 15 de febrero de 2018.

»Canseco, R. (2012). V alores para la calidad democrática. Revista Mexicana de Comunicación, 132, octubre-diciembre.

»Casas, M. (2011). Medios de comunicación, nuevas tecnologías y el futuro de la política. En Muñiz, C. (Coord.) Comunicación, política y ciudadanía. Aportaciones actuales al estudio de la comunicación política. México: Fontamara.

»Castillo, L. (2014). Medios y elecciones 2012: Viejos y nuevos desafíos para la comunicación política en México. Nóesis, Revista de Ciencias y Humanidades vol. 23, núm. 45, enero-junio. Disponible en http://www.redalyc.org/articulo. oa?id=85929886004 Fecha de consulta: 18 de octubre 2017.

» Díaz Jiménez, O. (2016). Comunicación política y compromiso cívico en México. Medios, campañas y su impacto en las actitudes y la participación cívica en la elección presidencial de 2012. México: Fontamara, Instituto Electoral del Estado de México, Universidad de Guanajuato.

» Echeverria, M. (2017). Infoentretenimiento periodístico en la cobertura de las elecciones. El caso de los debates presidenciales. Convergencias, vol. 24, núm.
74. Disponible en https://convergencia. uaemex.mx/article/view/4384 Fecha de consulta: 13 de enero de 2018.

» Echeverría, M. y Chong, B. (2014). La lógica mediática en los debates presidenciales, ¿del ejercicio cívico al espectáculo? Análisis de contenido. En Ortiz M., (Coord.). De los medios a las elecciones. El proceso electoral mexicano a través de la Red de Observatorios Mediáticos. México: CONEICC.

» El Economista (2018). Calendario del proceso electoral 2018. 3 de septiembre 2017. Disponible en https://www.eleconomista.com.mx/politica/Calendario-del-proceso- electoral-2018-20170903-0057.html Fecha de consulta: 13 de enero de 2018.

» Macías, H. (2007). Medios de comunicación, percepción de campañas y votantes tijuanenses durante el proceso electoral presidencial de 2006. XIV Anuario de Investigación de la Comunicación CONEICC. 
» Martínez, F. y Yañez, M. (2011). La actuación de las televisoras: nuevas reglas, viejas mañas. Redes.com (6). Recuperado de http://revista-redes.com/index.php/ revista- redes/article/view/201 Fecha de consulta: 23 de febrero de 2013.

» Meyer, J. Ahuactzin, C. Ríos, C. (2014). Papel de la comunicación mediática en la elección presidencial. En Meyer, J. (Coord.). Comunicación política y elecciones federales en México. Salamanca, Ed. Comunicación Social.

» Meyer, J., Ahuactzin, C., Ríos, C., Lara, C. López, R., Kuri, O. (2014). Spots políticos y su incidencia en la elección presidencial 2012. En Ortiz M., (Coord.). De los medios a las elecciones. El proceso electoral mexicano a través de la Red de Observatorios Mediáticos. México: CONEICC.

» Pareja, N. (2014). Ficción televisiva y comunicación política en el proceso electoral de 2012 en México. En Meyer, J. (Coord.). Comunicación política y elecciones federales en México. Salamanca, Ed. Comunicación Social.

»Sosa, G. (2011). Noticiarios, poder y democracia. En Vega, S. (Coord.). Ejes y transición de la República. México: UAM.

» Soto, L. (2014). Sistema nacional electoral. El gran reto. Revista Mexicana de Derecho Electoral, núm. 6, julio-diciembre. Disponible en http:// portalanterior.ine.mx/archivos2/portal/ servicio-profesional-electoral/concursopublico/2016-2017/primera-convocatoria/ docs/Otros/39-sist-nacional-electoral.pdf Fecha de consulta: 15 de febrero de 2018.

» Urrutia, A. y corresponsales (2018). Los comicios de este año, los más caros: 45 mil 620 millones de pesos. La Jornada, 6 de febrero de 2018. Disponible en http:// www.jornada.unam.mx/2018/02/06/politica/003n1pol fecha de consulta: 15 de marzo, 2018. 